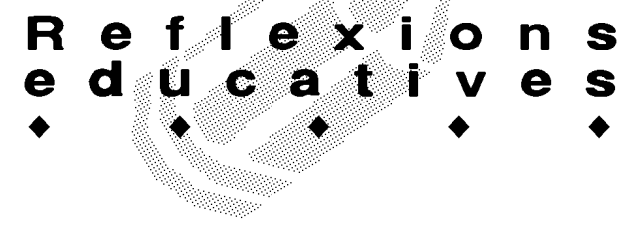

\title{
OBSERVAR, DESCOBRIR, FER: LA TASCA DELS ASSESSORS D'EDUCACIÓ VISUAL I PLÀSTICA
}

\author{
Joan Casals, Neus Coll, Rosa Dasca i Maite Fonts. Assessors d'Educació Visual i \\ Plàstica de l'Ajuntament de Tarragona. \\ Albert Macaya. Àrea de Didàctica de l'Expressió Plàstica a la URV.
}

En el model educatiu actual, el mestre generalista ha de donar resposta a un extens catàleg de demandes que tenen relació (com a mínim) amb diversos modes de coneixement, amb un ampli ventall de problemes relacionats amb els valors i les actituds, i amb les sempre complexes dinàmiques de la socialització. Enmig d'aquesta munió de reptes es troba també l'educació artística, un àmbit que requereix uns coneixements $\mathrm{i}$ una experiència específics. Com és sabut, al currícum actualment vigent l'educació artística comprèn la música i l'educació visual i plàstica.

La creació del mestre especialista en Educació Musical ha pogut contribuir a millorar les coses en aquesta àrea, pero en l'educació visual i plàstica molts docents es troben encara limitats per l'escassa formació inicial que els va proporcionar el seu pas pels estudis de mestre. Des de fa temps, l'opció triada per algunes escoles ha estat dotar-se d'un assessor extern que orienti les programacions d'aquesta àrea, treballant en coordinació amb el professorat d'Educació Infantil i Primària.

\section{El col-lectiu "Plàstica a l'escola"}

Joan Casals, Neus Coll, Rosa Dasca i Maite Fonts compten amb una llarga experiència com a assessors de l'àrea d'educació visual i plàstica a les nostres comarques. Fa també una colla d'anys que intercanvien experiències. Juntament amb altres professionals van endegar, ara fa uns 17 anys, el col-lectiu "Plàstica a l'escola". Aquest grup naixia davant la demanda d'una sèrie d'escoles públiques de la zona a la Diputació de Tarragona per tal de comptar amb orientació especialitzada en aquesta àrea. El nucli inicial el va constituïr l'estreta col-laboració d'Antoni Gurí i Pep Baluja a l'escola de Vila-rodona, experiència que aviat es va estendre a altres escoles fins a arribar a totes les comarques tarragonines.

El col-lectiu "Plastica a l'escola" va mantenir un treball coordinat, amb reunions periòdiques i amb línies de treball consensuades. Més tard, en fer-se càrrec de la iniciativa els Consells Comarcals, la contractació dels assessors del col-lectiu va passar a mans dels Ajuntaments, amb la conseqüent diversificació de criteris $\mathrm{i}$ pèrdua d'unitat d'objectius.

\section{El paper dels assessors}

Els quatre assesssors amb qui conversem, a més d'aquest origen comú, comparteixen el fet de treballar actualment per a les escoles públiques de l'àmbit de l'Ajuntament de Tarragona, i de continuar trobant-se regularment per posar en comú idees i experiències. En altres ciutats perviuen també altres grups de treball de l'antic col-lectiu.

Sobre com es duu a terme la seva tasca, Joan Casals defineix així el paper de l'assessor: "Intentem transferir els continguts al mestre, que s'encarrega de dur-los a la pràctica, supervisem el procés i després valorem els treballs, els avanços, les dificultats." Si bé aquesta és la tasca principal, Rosa Dasca puntualitza que, en ocasions, també s'ocupen "d'ajudar-los en altres àmbits, com ara representacions de teatre que requereixen escenografia, collaborar en setmanes culturals, etc. I a vegades també anem a les aules $\mathrm{i}$ treballem directament amb els nens. És el cas del projecte 'Tarragona Blava', un disseny d'unitat didàctica en el qual han col-laborat diverses escoles de Tarragona. Ha estat un encàrrec de l'Ajuntament, $i$ hi ha perspectives de fer-ne alguna publicació".

\section{Continguts proposats als mestres}

Dediquem una bona part de la conversa a repassar quins són els continguts que proposen als mestres. El ventall d'interessos és força ampli. Parlem del llenguatge plàstic, l'ús de materials i tècniques, l'aproximació a l'art, l'aprofitament de l'entorn com a punt de partida, i el desenvolupament de la percepció i l'observació.

Comencem per comentar com entenen i apliquen la noció de llenguatge plàstic. "Utilitzem els elements del llenguatge plàstic, però d'una manera oberta", diu Rosa Dasca. Joan Casals i Maite Fonts afegeixen: "El Ilen- 


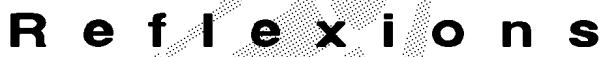

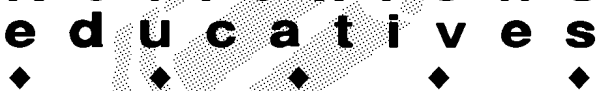

guatge plàstic ens serveix per a potenciar l'expressivitat del nen; s'ha de respectar la diversitat de respostes". "Les respostes sempre són diferents. D'una manera o altra, hi ha quelcom que guia tota la seva energia cap a respostes diversificades. El que cal és deixar espai perquè el nen i la nena responguin." Aclareixen que no els interessa fer un ús excessivament teòric de les nocions de llenguatge plàstic. En paraules de Casals, "no treballem des d'una vessant molt conceptualista, sinó a partir d'elements de l'entorn: sensacions, una imatge artística, elements que donen peu a treballar el color, el punt, la matèria..." Maite Fonts afirma: "Hi ha una part més conceptual, i després sempre una vessant més d'expressió. Si treballes les mescles de color, per exemple, ha d'haver-hi després un treball més lliure, d'expressió, amb els colors que han fet". Parlen també del procés tècnic, de l'ús de materials com a forma de vehicular l'expressió. Els interessa diversificar materials, tècniques i recursos.

Un altre aspecte que els interessa és el treball a partir de l'entorn. Com que la noció d'entorn és molt àmplia, Rosa Dasca la concreta en "el medi on viuen els nens i nenes, la seva realitat, les coses que tenen a prop". Per a Casals, en l'entorn hi ha multitud d'elements potencialment útils per a centrar-hi l'atenció. A més, un dels aspectes més interessants és el seu caràcter sempre canviant. Encoratgen els mestres a treballar sobre l'entorn amb mitjans plàstics. Les interrelacions són productives, l'observació i la percepció són estratègies clau. Joan Casals explica: "Utilitzem sovint elements de l'entorn en els treballs: elements vegetals, animals, objectes, tota mena de coses. Les experiències poden anar des de reunir petits 'museus' de coses trobades, aprofitar sortides per potenciar l'observació directa, fixarnos en l'observació de l'entorn que fa un determinat pintor..." Rosa Dasca coincideix a considerar el medi com una font de possibilitats: "Per educar la sensibilitat pots fer moltes coses, començant per les sensacions: observar l'espai obert del cel, o per contra el tràfec intens de la ciutat... tractar d'intergrar-te al medi". "Potenciar els aspectes sensorials. Deturar-nos en la pregunta: què veiem?" diu Casals. Rosa Dasca considera

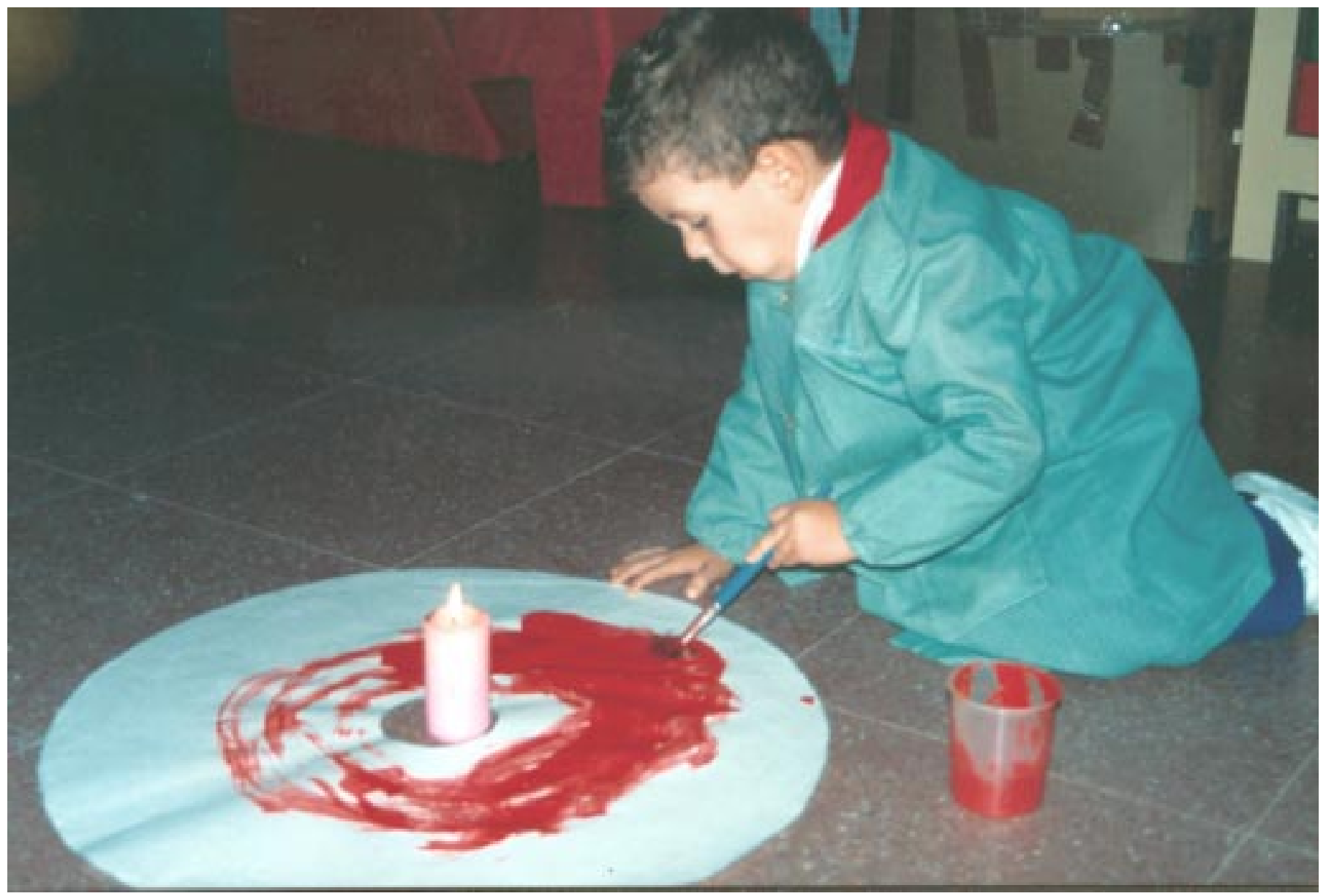




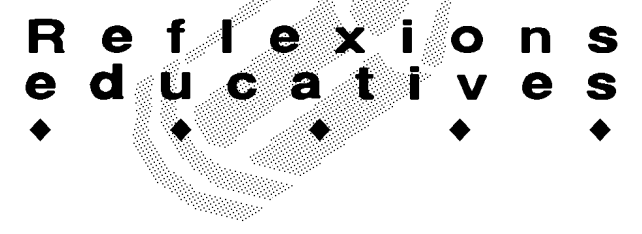

aquesta part dels continguts com la més difícil, però la qualifica de molt gratificant.

Sobre la qüestió de l'apreciació estètica, els membres del grup tenen diverses maneres d'introduir l'art. Joan Casals i Rosa Dasca treballen sovint en projectes entorn d'un artista rellevant. Miró, Kandinsky, Goya, Moore, han estat objecte de treball en les seves sessions. Maite Fonts i Neus Coll se serveixen d'imatges artístiques per tal de destacar-ne algun aspecte formal: "Aprofitem una obra plàstica per treballar algun aspecte que t'interessa: el color, la forma, el traç..." En una imatge artística, però, es poden descobrir moltes coses més que els seus aspectes formals. No els agrada parlar d'interpretació, però sí que fan referència a l'expressivitat que conté una imatge. Maite Fonts puntualitza: "Treballem d'entrada les sensacions, l'expressió que va voler comunicar l'autor. Poden aparèixer preguntes com: 'estava content, trist, enfadat'...?"

Utilitzen el material que tenen a l'abast, com les reproduccions de llibres i les diapositives; però la visita al museu és sempre una experiència més completa. Com diu Dasca, "els museus s'estan obrint a les escoles i això és interessant. Ara es fan més accessibles als escolars." Neus Coll destaca experiències d'altres tipus, com els Camps d'Aprenentatge, que també constitueixen vies d'aproximació a l'art amb què es pot comptar. Fonts apunta un altre argument a favor de visitar museus 0 Camps d'Aprenentatge: "No sols és important per als nens, per a l'escola també és molt enriquidor. A vegades plantegem massa demandes als mestres, com si haguessin de 'saber de tot'. És important comptar amb aquests suports externs."

\section{El currículum de l'administració}

Un altre tema que apareix a la conversa és el currículum de l'administració. Pot considerar-se un ajut útil per als mestres en l'àrea d'educació visual i plàstica? Neus Coll i Maite Fonts coincideixen a considerar-lo una bona eina en comparació amb les dinàmiques de treball més basades en la inèrcia, vigents encara en tantes escoles. Joan Casals planteja algunes objeccions: "EI llenguatge no sempre és adequat. En alguns moments pot ser indesxifrable per als mestres generalistes. A més, és excessivament ampli." Maite Fonts es mostra d'acord amb el fet que la terminologia emprada pot comportar dificultats d'interpretació i aplicació per al mestre, però el seu caràcter genèric i obert és valorat positivament per Neus Coll: "Això també és un avantatge. El fet que els objectius no siguin excessivament concrets deixa més possibilitats obertes." "De fet, tot el que hem volgut treballar hi cabia", afegeix Rosa Dasca. No obstant això, tots els participants a la conversa coincidim que el currículum de l'àrea d'educació visual i plàstica té un cert aire de calaix de sastre; es tracta d'un conglomerat de diverses tradicions pedagògiques, des de les que ens remeten a l'expressió espontània fins a idees més properes a les noves tendències relacionades amb el concepte de cultura visual.

\section{La relació entre l'assessor de plàstica i els mestres}

Al llarg de la conversa va apareixent la qüestió de la relació de l'assessor de plàstica amb els mestres. Consideren que, en general, l'actitud del mestre és receptiva. Però moltes vegades hi han d'introduïr conceptes, criteris i metodologies que són noves per als docents amb qui col-laboren. "El discurs que tu desplegues té molt a veure amb el canvi de mentalitat que pugui fer el mestre en relació a temes com l'art o la creativitat", diu Joan Casals. Rosa Dasca compara aquest fet amb l'evolució que ells mateixos han de dur a terme per tal d'actualitzar el seu treball: "Nosaltres hem sortit del plantejament del Llenguatge Plàstic, però ara, per exemple, ens comencem a interessar per l'Educació per a la Cultura Visual".

Els canvis que tracten d'introduïr a l'escola no tenen a veure només amb els conceptes. També en la metodologia miren d'introduir maneres de fer diferents. Coincideixen a observar una excessiva preocupació, en molts mestres, pel resultat final. Consideren que el que importa és el procés seguit pels nens i les nenes, independentment que desemboqui o no en un treball "bonic", susceptible de ser inclòs en algun àlbum. Una altra qüestió en què cal propiciar un canvi de criteris en el mestre és en els referents artístics que utilitzen. L'art contemporani no sempre és un referent proper per als mestres a qui assessoren. Tal com ho explica Maite Fonts, "si poses alguna imatge una mica 'estranya' a la classe, a ningú no li agrada. Però si cada dia la van veient, a l'hora de treure-la fins i tot aquells a qui no agradava se l'han fet seva. Cal que aquestes imatges, l'art contemporani, estiguin a l'escola, el que s'està fent ara. Que les vegin tant els nens com els mateixos mestres." Joan Casals apunta: "És que no hi ha d'haver una estètica única, hi ha moltes possibilitats". "Està molt bé veure i treballar Miró o Picasso, però també es poden introduïr altres manifestacions més recents; fins i tot la 'performance' o el vídeo hi poden tenir cabuda" afirma Fonts. Els altres participants a la conversa s'hi mostren d'acord, i comenten que, habitualment, els nens accepten sense prejudicis aquesta mena de propostes. Les idees preconcebudes són més aviat cosa dels adults. No obstant això, Rosa Dasca destaca el fet que hi ha 


\section{$R$ e f e e $x$ i \\ e d u c a t i ves}

mestres amb molta curiositat i molt receptius cap a aquests temes: "I no són necessàriament els més joves. No té a veure amb l'edat, sinó amb la persona. A vegades els més inquiets són els que porten més anys de docència." "Té a veure amb el tipus de diàleg que arribes a mantenir amb cada mestre" afirma Casals. "Si tu ets capaç de generar el desig de conèixer en el mestre, serà capaç de transmetre aquest mateix desig als nens i les nenes".

\section{Mancances}

Davant la pregunta de quines mancances detecten, quant a infrastructura o condicions d'altra mena per treballar l'educació visual i plàstica, Neus Coll és rotunda: "Més hores!" (l'assentiment de tots els participants a la conversa és immediat). La mancança de temps per treballar aquesta àrea limita molt les possibilitats, i més encara considerant tot el desplegament d'utillatge que s'ha de fer per començar i tot l'enrenou de materials i treballs que cal recollir en acabar. També es lamenten de la manca d'aules específiques de plàstica a moltes escoles, o de l'ús escàs que se'n fa en altres. "Darrerament no hi ha tant d'interès per equipar les aules de plàstica com per comptar amb altres mitjans. Es dediquen molts més recursos a equipaments informàtics, per exemple" comenta Maite.

En qualsevol cas, el seu treball continua constituint un repte engrescador. Casals destaca el valor cognitiu de la plàstica: "el pensament genera imatges, les imatges són una forma de pensament. No només les arees 'científiques' generen pensament". Maite Fonts apunta un barem més espontani per valorar l'educació visual i plàstica: "Pregunta als nens quina és l'àrea que més els agrada".

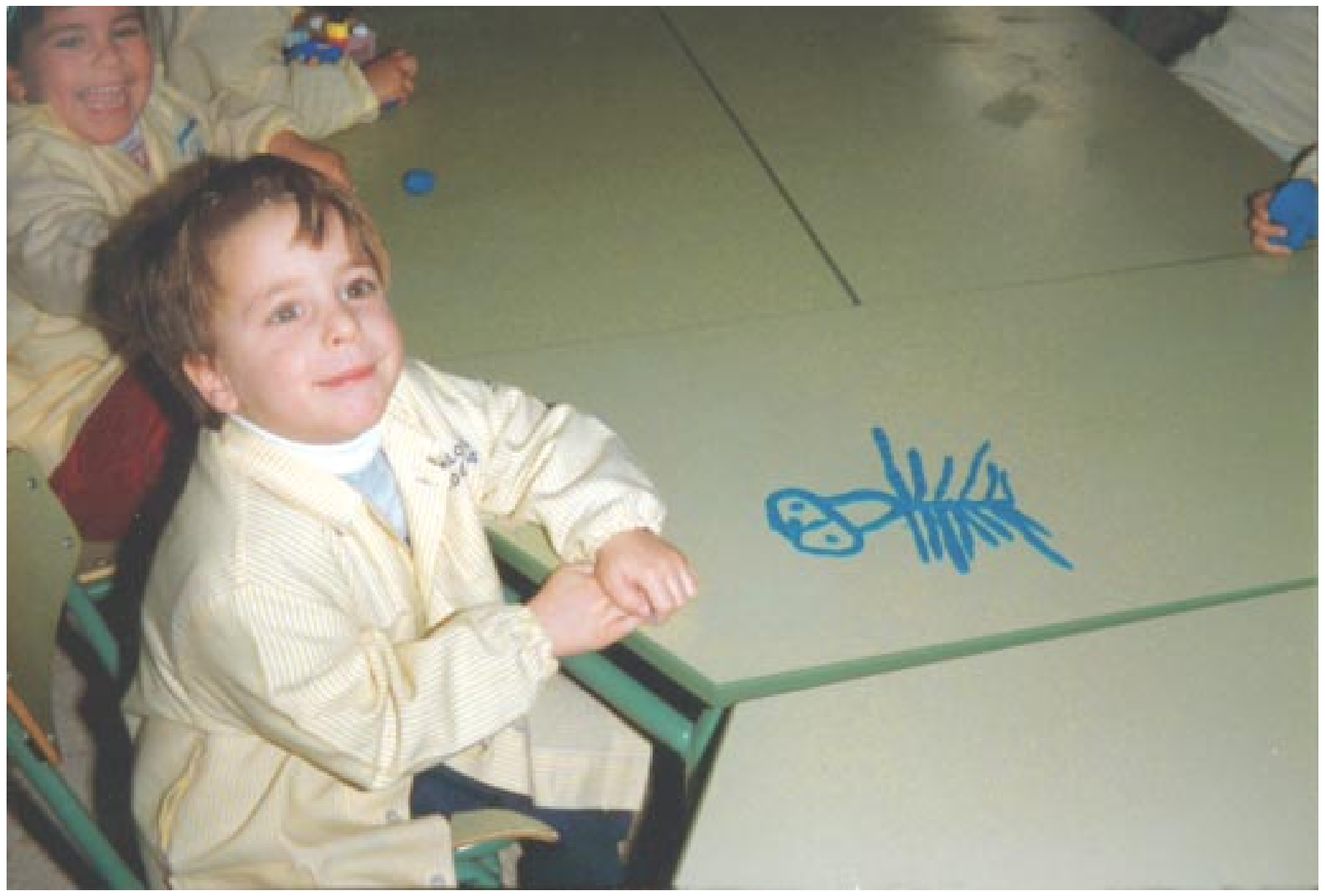

